\title{
POTENTIAL GEOLOGIC ISSUES OF VON KÁRMÁN CRATER REVEALED BY MULTISOURCE REMOTE SENSING DATA
}

\author{
Z. G. Meng ${ }^{1,2,3, * \text {, H. H. Wang }}{ }^{1}$, S. B. Chen ${ }^{1}$, J. S. Ping ${ }^{3}$, Q. Huang ${ }^{4}$, Z. C. Cai ${ }^{2}$, Y. Z. Wu ${ }^{5}$, L. X. Xing ${ }^{1}$, Y. G. Wu ${ }^{1}$ \\ College of Geoexploration Science and Technology, Jilin University, China - (mengzg, wanghh, xinglx, wuyg)@jlu.edu.cn \\ ${ }^{2}$ State Key Laboratory of Lunar and Planetary Sciences, Macau University of Science and Technology, Macau - zccai@must.edu.mo \\ ${ }^{3}$ Key Laboratory of Lunar and Deep Space Exploration, National Astronomical Observatory, CAS, China - jsping@ bao.ac.cn \\ ${ }^{4}$ Institute of Geophysics and Geomatics, China University of Geosciences, China - qianhuang@cug.edu.cn \\ ${ }^{5}$ Purple Mountain Observatory, Chinese Academy of Sciences, China. - yunzhaowu@qq.com
}

KEY WORDS: Von Kármán Crater, SPA, Composition, LOLA data, Bouguer Gravity Anomaly, Brightness Temperature, Potential Geologic Issues

\begin{abstract}
:
Von Kármán crater is the landing area for CE-4 mission, which provides a chance to further study the evolution of South-Pole Aitken basin. In this paper, the topography, composition, temperature and deep structures of Von Kármán crater are systematically studied with LRO LOLA data, Clementine UV-VIS data, CE-2 CELMS data, and GRAIL data. Several potential geologic issues are postulated as follows: (1) There exists a difference for the southern and northern parts of the crater floor in topography. The surface topography is influenced by Leibnitz and Finsen events. (2) There exists an FTA-rich material in depth layer of the crater floor, and the later bombardments exposed the original material in the crater floor. And the material in depth is homogeneous. (3) The composition apparently changes with depth, and there exist a warm anomaly in the northern part of the crater floor and a cold anomaly in the southern part. (4) A large amount of magma has been uplifted after Von Kármán M impact event, and the crust has been melted several times and condensed into dense basalt layer. Generally, this is a good place to measure the material from the original SPA basin and the material from the depth layer of the Moon for the CE-4 landing site.
\end{abstract}

\section{INTRODUCTION}

On January 3, 2019, Chang'E-4 lunar probe was successfully landed at $\left(177.588^{\circ} \mathrm{E}, 45.457^{\circ} \mathrm{S}\right)$ in Von Kármán crater, which is located in central regions of the South Pole-Aitken (SPA) basin. This is the first soft landing of human spacecraft and insitu rover on the lunar farside, which brings about a new era of the lunar exploration.

SPA basin has a latitude of $40^{\circ} \mathrm{S}$ to $60^{\circ} \mathrm{S}$ and a longitude centred at around $180^{\circ}$ and it is the largest and oldest crater in the Moon with a diameter of about $2600 \mathrm{~km}$ (Ouyang, 2005; Jolliff, 2012). The distribution of material compositions in the SPA basin as well as the formation and evolution of the basin have always been the focus of the scientific research but still in debate (Zhang et al., 2011; Kim et al., 2012; David and Daniel, 2012; Pasckert et al., 2017). Some small-scale distribution of olivine, plagioclase, spinel and high-calcium pyroxene were also found in the SPA basin based on Clementine, Kaguya and Chandrayaan Moon Mineralogy Mapper $\left(\mathrm{M}^{3}\right)$ (Moriarty et al., 2013; Pieters et al., 2001; Ohtake et al., 2009; Kramer et al., 2013; Yamamoto et al., 2012). The National Research Council (2007) has proposed 35 scientific goals for the Constellation Program and Snape et al. (2010) thought that most of the goals can be investigated across the SPA basin and identified Von Kármán crater as one of the particularly important sites for exploration.

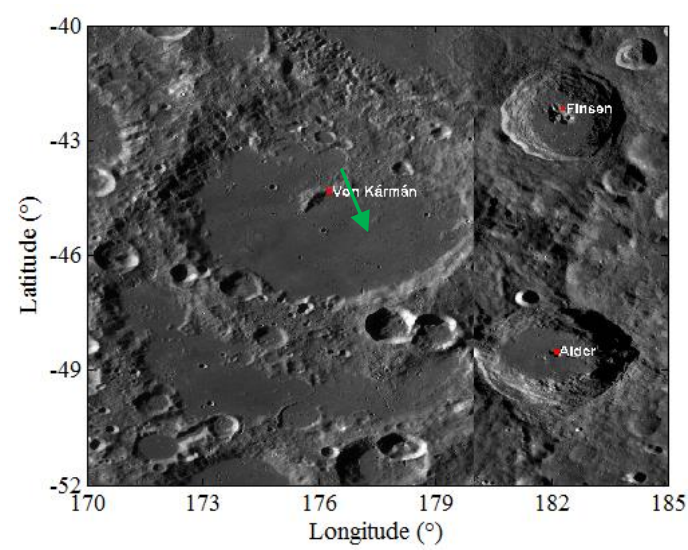

Figure 1 Image of Von Kármán crater

Von Kármán crater, ranging from $42^{\circ} \mathrm{S}$ to $48^{\circ} \mathrm{S}, 172^{\circ} \mathrm{E}$ to $180^{\circ} \mathrm{E}$, is a crater of pre-Nectarian located in the middle of SPA (Figure 1). The diameter of Von Kármán crater is about $180 \mathrm{~km}$. The study of Von Kármán crater may provide a chance to further understand the formation, composition, and structure of SPA basin. There is a small portion of an uplift appearing in the central part of Von Kármán crater (Snape et al., 2010). There also exist mare basalt flows filled inner the crater and the flows are about 3.35 Ga (Figure 1) (Haruyama et al., 2009; Pasckert et al., 2017). Leibnitz, Finsen, and Alder craters are located in the north, northeast, and southeast of Von Kármán crater, respectively. The tiny fluctuate of topography in Von Kármán

\footnotetext{
* Corresponding author
} 
crater is suitable for landing and younger basalts are appeared there (Pasckert et al., 2017). Therefore, Von Kármán crater is the most likely area to excavate the material from the lower lunar crust and upper mantle, which is expected to obtain a new understanding of early evolution history of the Moon (Xiao et al., 2016; Meng et al., 2018).

In this study, the topography, composition, crust structure and microwave thermal radiation characteristics of Von Kármán crater are systematically and comprehensively studied using the latest image, spectrum, elevation, gravity and microwave data.

\section{GEOLOGIC BACKGROUND}

The study on the deep crust and upper mantle is a key issue in the current lunar science research, which is important to understand the divergence in the early formation stage and to investigate the origin of the dichotomy of the Moon (National Research Council, 2007). Xiao et al. (2016) proposed that SPA basin is the most likely area to excavate material from the mantle, where the central peaks, the impact ejecta, and the impact melting breccia provide the proper sampling candidates. Area inner the basin and the ejecta are all suitable for sampling mantle material. Although the excavated mantle material may be covered by the regolith and basalts, which are again excavated by the later-formed craters (Xiao et al., 2016). Therefore, SPA basin is an ideal area to study the material from deep crust and upper mantle (Xiao et al., 2016).

Von Kármán crater is located in the middle of SPA basin. Figure 2 is the geologic map of the crater from U.S. Geological Survey, which ranges from $170^{\circ} \mathrm{E}$ to $190^{\circ} \mathrm{E}$ and from $30^{\circ} \mathrm{S}$ to $50^{\circ} \mathrm{S}$. Here, Im represents mare materials of dark plains, Ig represents material of grooves and mounds covered by craters, and $\mathrm{Nc}$ represents units older than Imbrium basin and younger than Nectaris basin (Stuart-Alexander, 1978). Figure 2 indicates that the entire crater floor is covered by the mare basalt in Imbrian age. Also, Figure 1 and Figure 2 show that Von Kármán crater superposed on an older crater named Von Kármán M, which is likely to penetrate the entire lunar crust and excavate the material from the mantle. Moreover, this area is rich in Thorium and KREEP (Pasckert et al., 2017). Furthermore, Von Kármán crater is far from highlands and near the centre of SPA basin, which means the relatively less contamination from the highlands materials. Therefore, Von Kármán crater is an ideal area for studying deep lunar crust and mantle materials.

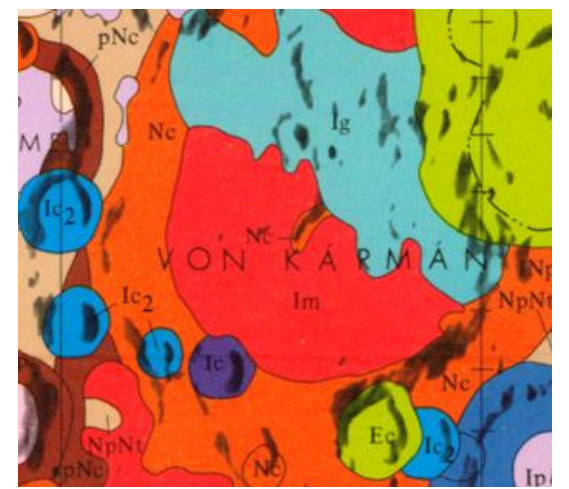

Figure 2 Geologic map of Von Kármán region (https://www.lpi.usra.edu/resources/mapcatalog/usgs/)

Snape et al. (2010) estimated crustal thickness of SPA basin using a dual-layered crust-moho depth model and Kaguya topography data. The results show that the bulk melt created during Von Kármán impact event might represent the entire lunar crust and that the uplifted materials might postulate some clues about the crust-mantle boundary. Thus, the comprehensive study of Von Kármán crater is of great significance to better understand the formation mechanism of the SPA basin and the evolution of the Moon.

\section{MULTI-SOURCE REMOTE SENSING ANALYSIS}

The topography, composition, temperature, and deep structure are systematically analysed by combining LRO LOLA data, Clementine UV-VIS data, CE-2 CELMS data and GRAIL data.

\subsection{Topography}

The topography of Von Kármán crater is studied using the LOLA data from the Lunar Reconnaissance Orbiter (LRO) (Feature 3). The crater floor is about $200 \mathrm{~km}$ from east to west and $160 \mathrm{~km}$ from north to south, with a total area of about $37594.5 \mathrm{~km}^{2}$. The average elevation in the crater floor is about $4 \mathrm{~km}$ lower than its east vicinity and about $2.5 \mathrm{~km}$ lower than its south vicinity. The highest site in the crater is located on the central peak, $\left(175.9^{\circ} \mathrm{E}, 44.5^{\circ} \mathrm{S}\right)$, with the elevation of $-4323.8 \mathrm{~m}$, and the lowest one is located in a small crater in the northern part of the crater floor, $\left(174.9^{\circ} \mathrm{E}, 44.3^{\circ} \mathrm{S}\right)$, with the elevation of $-6621.3 \mathrm{~m}$. The average elevation of Von Kármán crater floor is about $-5852.0 \mathrm{~m}$

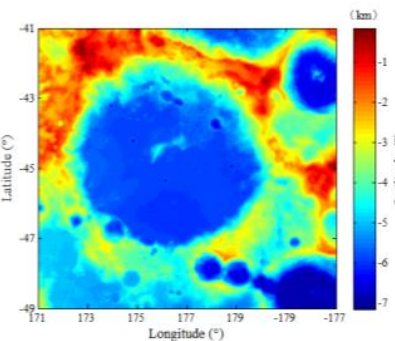

(a) Elevation map

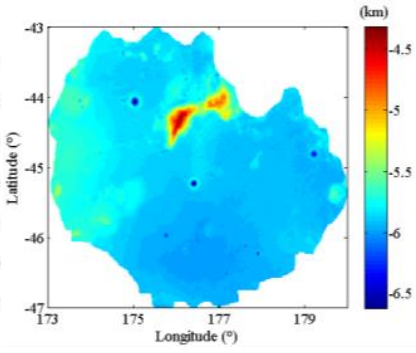

(b) Crater floor
Figure 3 Elevation map of Von Kármán crater and its floor (http://pds-geosciences.wustl.edu//ro/lro-l-lola-3-rdrv1//rolol_1xxx/data/lola_gdr/cylindrical/float_img/)

Within Von Kármán crater, the average elevation in the southern part, $-5963.4 \mathrm{~m}$, is lower than that in the northern, $5848.4 \mathrm{~m}$. In the southern part, the topography fluctuates gently and there are few large craters, indicating the younger of the area in age. Whereas, the northern part has a complex topographic structure and there exist several large craters, indicating that it is relatively older in age. The results coincide well with the conclusion made by Haruyama et al. (2009).

The central peak is about $45.5 \mathrm{~km}$ in length and about $13.7 \mathrm{~km}$ in width, and the area is $800.75 \mathrm{~km}^{2}$. It is obviously divided into the eastern part and western part. The highest elevation is about $-4323.8 \mathrm{~m}$ in the western part and about $-5835 \mathrm{~m}$ in the eastern part. Moreover, the surface roughness and fractal dimension show a clear difference between the eastern and western parts of the central peaks, which hints that they likely belong to different geologic units.

The rim of Von Kármán crater is irregular and only the southeast rim keeps well. Serious degradation of the rim occurs in the northeast part, which means that the crater is experienced greatly impact by Leibnitz and Finsen impact events. What's 
more, Figure 1 postulates abundant linear structures orientating to Leibnitz, Finsen, and Alder craters, validating the strong influence on the shallow layer of Von Kármán crater from the nearby impacting events.

Interestingly, there occurs a special terrain in the western part of the crater. Snape et al. (2010) thought that there is a volcanic dome and the intruded or extruded basalts samples could be collected here. However, combined with the three-dimensional model and topographic profile, the uplifted terrain here is continuous from the western crater rim to the crater centre, and the elevation is gradually decreased along the profile. Thus, the terrain is re-interpreted as a huge gravitational landslide instead of basaltic intrusions or extrusions. Additionally, the material from landslide masses enters into the central part of the crater floor about $60 \mathrm{~km}$, indicating that this is a new geomorphic evolution form in the lunar surface. The reason for special geomorphology evolution deserves to be further studied.

\subsection{Compositions}

The composition distribution is a key to better understand the formation and evolution of the SPA basin (Kim et al., 2012; Pasckert et al., 2017). Clementine UV-VIS data provide a good candidate to estimate the $\left(\mathrm{FeO}+\mathrm{TiO}_{2}\right)$ abundance (FTA) in the SPA basin (Lucey et al., 2000; Gillis et al., 2004; Pasckert et al., 2017), which is also employed in this study (Figure 4). The spatial resolution is about $0.00625^{\circ}$.

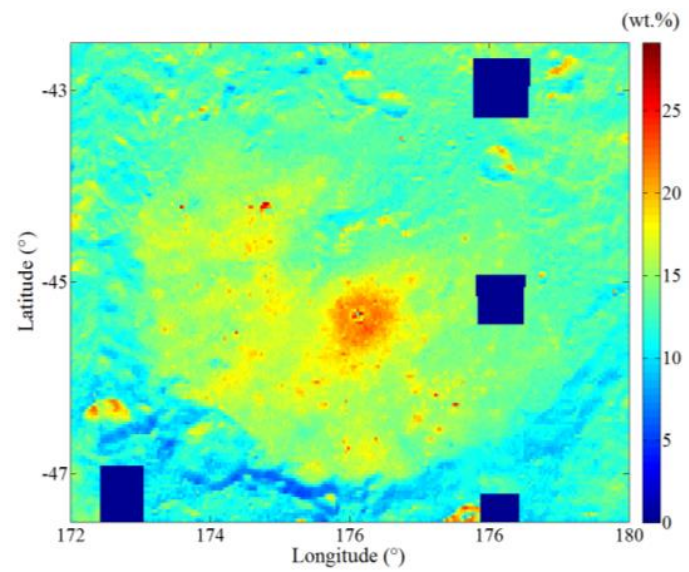

Figure 4 FTA map of Von Kármán crater

Figure 4 shows that the FTA in the crater floor is obviously higher than the surrounding regions. Moreover, in the crater floor, the FTA ranges from $12 \mathrm{wt} . \%$ to $25 \mathrm{wt} . \%$, and it reaches about 27 wt.\% in certain craters. However, the distribution of FTA is rather uneven. In detail, the regions with relatively higher FTA is continuously distributed in the southern part, while the FTA in the northern part largely ranges from $15 \mathrm{wt} . \%$ to $20 \mathrm{wt} . \%$ with a discontinuous distribution. What's more, the distribution of the FTA indicates the following two regularities.

Firstly, there exists a strong correlation between the FTA and the craters in the crater floor. The relatively higher FTA also appears at craters at $\left(176.00^{\circ} \mathrm{E}, 46.81^{\circ} \mathrm{S}\right),\left(176.96^{\circ} \mathrm{E}, 46.19^{\circ} \mathrm{S}\right)$, $\left(177.26^{\circ} \mathrm{E}, 46.26^{\circ} \mathrm{S}\right),\left(177.29^{\circ} \mathrm{E}, 46.61^{\circ} \mathrm{S}\right),\left(177.54^{\circ} \mathrm{E}, 46.36^{\circ} \mathrm{S}\right)$, $\left(174.82^{\circ} \mathrm{E}, \quad 44.97^{\circ} \mathrm{S}\right), \quad\left(174.81^{\circ} \mathrm{E}, \quad 44.28^{\circ} \mathrm{S}\right), \quad$ and their surroundings. Especially at the largest crater of $\left(176.13^{\circ} \mathrm{E}\right.$, $45.41^{\circ} \mathrm{S}$ ) with $3.8 \mathrm{~km}$ in diameter, there occurs an extensive region with the highest FTA in the crater floor, up to $0.9 \mathrm{~km}$ away from the crater centre.
Secondly, the distributions of the regions with higher FTA are directional. They are largely longer in northeast direction but shorter in northwest direction.

Combined with the findings in Section 3.1, it again implies the strong impact on the surface compositions from the impact events in Leibnitz and Finsen craters and probably other regions in the direction. That is, the compositions in the superficial layer of Von Kármán crater are strongly altered by the impact ejecta from the nearby regions. Moreover, the strong correlation between high FTA and craters implies that there is likely a FTA-rich material in depth, and the later bombardments exposed the original material in the crater floor.

Additionally, the highest FTA occurs in the largest crater at $\left(176.13^{\circ} \mathrm{E}, 45.41^{\circ} \mathrm{S}\right)$ and its vicinity, which is similar in value to the craters with higher FTA, indicating the homogeneity of the material in depth.

According to the relationship between composition and age of basalts (Hiesinger et al., 2003; Haruyama et al., 2009), the younger basalts should have a higher FTA. The FTA in depth is more than $20 \mathrm{wt} . \%$ indicated by excavated material, hinting that the basalts here are very young. Therefore, the analysis of basalt samples in this area will provide important clues to improve understanding the basaltic volcanism in the lunar farside.

\subsection{Temperature Structure}

The microwave sounder (CELMS) aboard the Chang'E satellites is sensitive to the temperature and composition of substrate regolith (Zheng et al., 2012; Meng et al., 2016, 2017, 2018, 2019). The CE-2 CELMS data are used to generate the brightness temperature $\left(T_{B}\right)$ maps of Von Kármán crater (Figure $5)$. The process is followed by the procedure suggested by Meng et al. (2018), and the $T_{B}$ maps at noon and night are generated

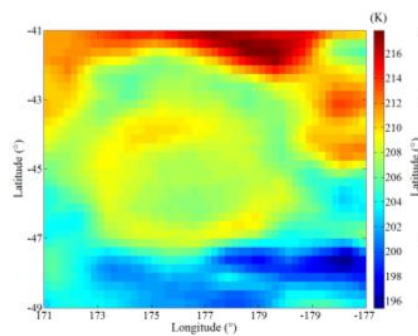

(a) noon, $3.0 \mathrm{GHz}$

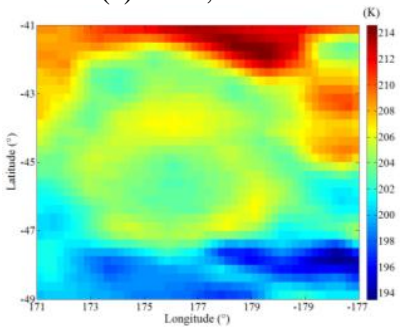

(c) night, $3.0 \mathrm{GHz}$

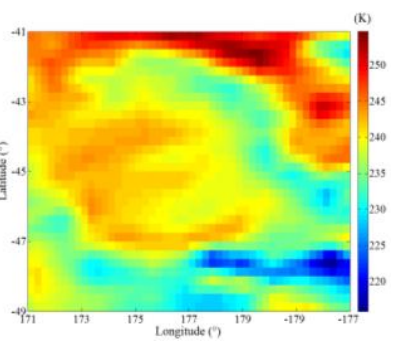

(b) noon, $37.0 \mathrm{GHz}$

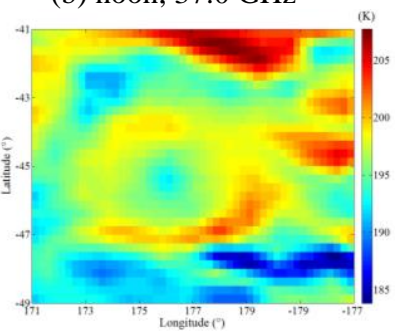

(d) night, $37.0 \mathrm{GHz}$
Figure $5 T_{B}$ maps of Von Kármán crater

Referred to the interpretation by Stuart-Alexander (1978), the geologic structure here is fairly simple in Von Kármán crater, and the crater floor is only Imbrian basalt. However, Figure 5 postulates several complicated $T_{B}$ behaviours. 
Firstly, at noon, the relatively higher $T_{B}$ occurs in the northern part of the crater floor, while the $T_{B}$ in the southern part is about $4 \mathrm{~K}$ lower than that in the northern part. Moreover, the area with higher $T_{B}$ in the northern part is much larger in $37 \mathrm{GHz}$ map than that in $3.0 \mathrm{GHz}$ map.

Secondly, at night, there exists an extensive region with relatively lower $T_{B}$ in the southern part centred at the crater $\left(176.13^{\circ} \mathrm{E}, 45.41^{\circ} \mathrm{S}\right)$. Again, the higher $T_{B}$ occurs in the northern part.

Thus, two important conclusions can be obtained.

Firstly, the materials in the crater floor are not homogenous as indicated by the visible data. At least, the materials in the northern part of the crater floor are different from those in the southern part. Moreover, considering the penetration capabilities of the microwave (Campbell et al., 2008), the apparent change of the $T_{B}$ with frequency indicates that the material in the northern part obviously changes with depth.

Secondly, there exist warm anomaly in the northern part of the crater floor, which shows higher $T_{B}$ at noon and night, and cold anomaly in the southern part with lower $T_{B}$ through a whole day There is still in debate for the causes of the warm and cold anomalies. The in-situ exploration by the CE-4 mission may give a rational interpretation for this work.

\subsection{Deep Structure}

Internal structures of the lunar crust and mantle are one of key issues in the lunar exploration. Gravity field analysis methods are widely used to pursuit the deep structure of the Moon (Wieczorek, 2007). Snape et al. (2010) considered the crust in SPA is extremely thin using Kaguya topography and gravity data (Ishihara et al., 2009). Using the latest Grail gravity data and topography data of the Moon, the deep structure in Von Kármán crater is evaluated with the generated Bouguer gravity anomaly map (Huang et al., 2018) (Figure 6).

Figure 6 shows that there occurs a positive Bouguer gravity anomaly in the south edge of Von Kármán crater, which is corresponding to the obvious negative gradient anomaly. There exists a linear structure along the south edge of Von Kármán crater, which indicates an obvious dike with a length of about $180 \mathrm{~km}$. This means a large amount of magma uplifted after Von Kármán M impact event. Thus, the Von Kármán impact event may likely excavate the mantle material in depth, which is then mixed with basalt formed after the later magma eruption. However, it's difficult to distinguish the material mentioned above from the mineral maps with a spatial resolution in current scale.

The Von Kármán event is repeated hit on Von Kármán M event, which brought about the local melt of the lunar crust because of the high temperature. At last, the lunar crust here is formed, and the thickness is less than $5 \mathrm{~km}$. Combined with gravity and topography data, the porosity of Von Kármán crater is about $9 \%$ in average, which is slightly smaller than the simulation result, about $12 \%$. It means that the crust in the crater has been melted for several times and condensed into dense layer at last.
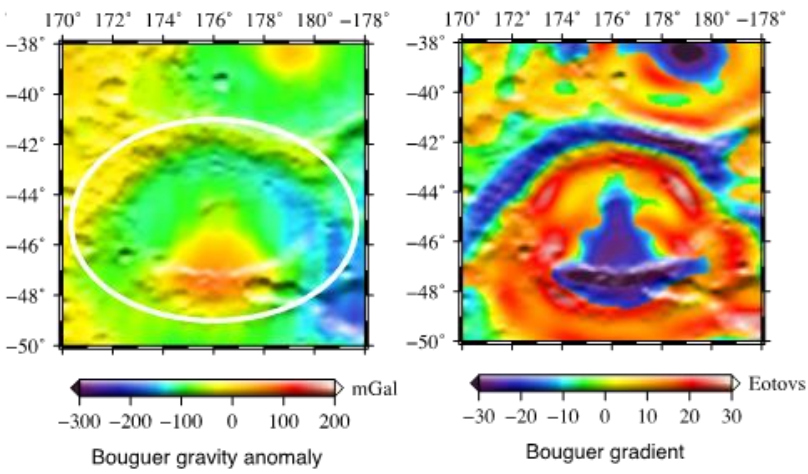

(a) Bouguer gravity anomaly (b) Bouguer gravity gradient Figure 6 Bouguer gravity anomaly and Bouguer gravity gradient map (http://pds-geosciences.wustl.edu/)

\section{CE-4 LANDING SITE}

Centred at the landing site $\left(177.588^{\circ} \mathrm{E}, 45.457^{\circ} \mathrm{S}\right)$, the geography, elevation and FTA maps are generated using WAC image, LOLA data, and Clementine UV-VIS data (Figure 7).

Figure 7(a) indicates that there only exist smaller craters, Figure 7(b) hints a fairly flat surface, and Figure 7(c) postulates a considerably even FTA distribution. However, there exist abundant linear structures and the chain impact craters in Figure 7(a). Moreover, the elevation also shows linear terrains orientating to the northeast direction. This again validates the strong influence of the Leibnitz and Finsen events on the site.

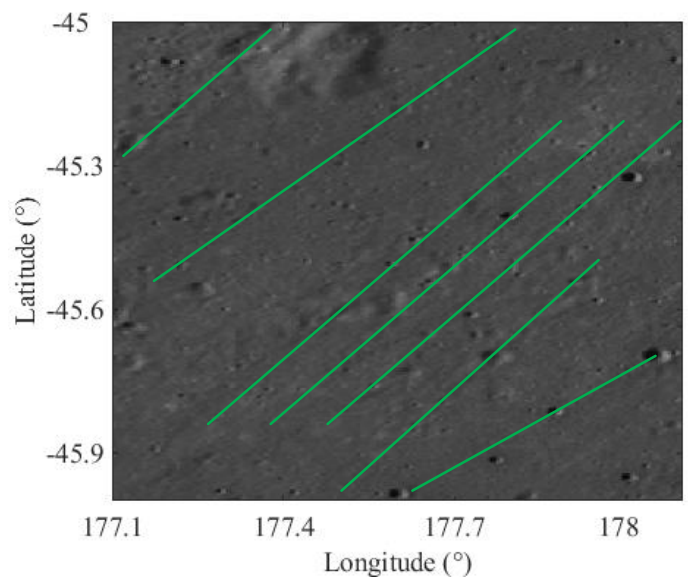

(a) WAC image

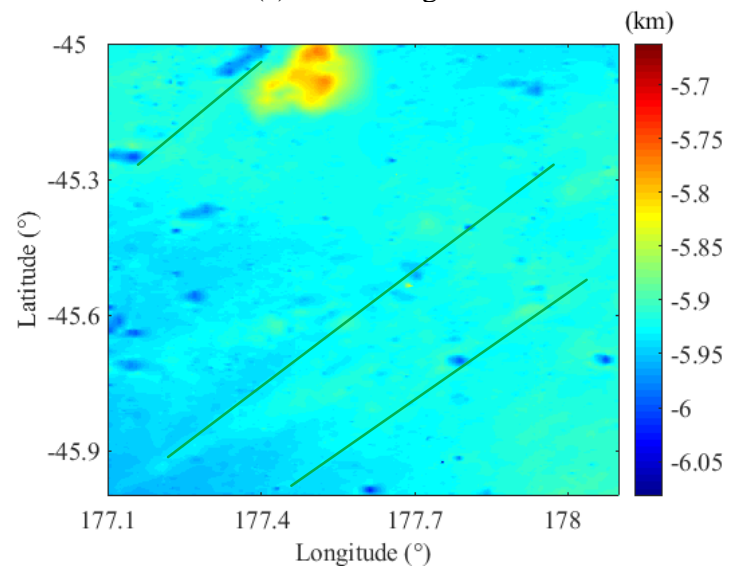

(b) Elevation map 


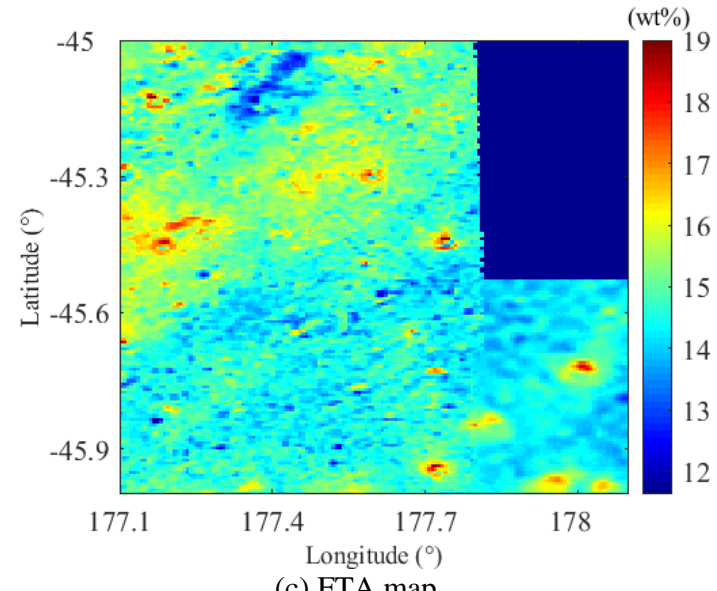

(c) FTA map

Figure 7 Geopography, elevation and FTA maps of landing site

Figure 7(c) indicates that the FTA is unevenly distribution in the landing site, where the higher FTA occurs in the northwest part and the lower FTA occurs in the southeast part. However, the distribution is also in line towards the northeast direction, indicating the shallow layer of the landing site is totally covered by the ejecta from the impact event in the northeast part. Interestingly, the craters and their surroundings are materials with higher FTA, indicating that the material in depth is rich in FTA.

Therefore, the strong contamination by the ejecta makes it difficult to understand the difference in the northern and southern parts of the crater floor. Also, it may mask the real causes for the cold anomaly indicated by Figure 5 .

Fortunately, The Leibnitz and Finsen craters are also in the SPA basin, meaning that the CE-4 mission will obtain materials from the original SPA basin as indicated by ejecta in the shallow layer and materials from the depth as indicated by the FTA-rich materials.

\section{CONCLUSION}

In this study, the geomorphology, composition, temperature and deep structures of Von Kármán crater are systematically studied with LRO LOLA data, Clementine UV-VIS data, CE-2 CELMS data, and GRAIL data. The main conclusions are shown as follows.

(1) The topography map indicates the difference of the southern and northern parts of the crater floor. Moreover, the eastern and western parts of the central peaks likely belong to different geologic units. The degraded crater rim and the linear structures indicate the strong influence on the shallow layer of Von Kármán crater from the nearby Leibnitz and Finsen impact events.

(2) The FTA map implies that there exists a FTA-rich material in depth layer of the crater floor, and the later bombardments exposed the original material in the crater floor. Also, the craters with higher FTA also hint that the material in depth is homogeneous.

(3) The $T_{B}$ behaviours show the composition changes with depth. Moreover, there exist a warm anomaly in the northern part of the crater floor and a cold anomaly in the southern part.
(4) The Bouguer gravity anomaly indicates a large amount of magma uplifted after Von Kármán $M$ impact event, and the smaller porosity of crust at Von Kármán crater indicates the crust has been melted several times and condensed into dense basalt layer.

(5) The geopography, elevation and FTA maps of CE-4 landing site indicate that this is a good place to measure the material from the original SPA basin and the material from the depth of the Moon.

\section{ACKNOWLEDGEMENTS}

This work was supported by the National Natural Science Foundation of China under Grants (41490633, 41371332, 41802246), the opening fund of State Key Laboratory of Lunar and Planetary Sciences (Macau University of Science and Technology) (Macau FDCT grant No. 119/2017/A3), and the Science and Technology Development Fund of Macau under Grant 0012/2018/A1.

\section{REFERENCES}

Campbell, B.A., Carter, L.M., Hawke, B.R., Campbell, D.B., Ghent, R.R., 2008. Volcanic and impact deposits of the moon's Aristarchus Plateau: a new view from earth-based radar images. Geology, 36(2), 135-138.

David, A.K., Daniel, D.D., 2012. A global lunar landing site study to provide the scientific context for exploration of the Moon. USA:LPI-JSC Center for Lunar Science and Exploration.

Gillis, J.J., Jolliff, B.L., Korotev, R.L., 2004. Lunar surface geochemistry: Global concentrations of $\mathrm{Th}, \mathrm{K}$, and $\mathrm{FeO}$ as derived from lunar prospector and Clementine data. Geochim. Cosmochim. Ac., 68(18), 3791-3805.

Haruyama, J., Ohtake, M., Matsunaga, T., Morota, T., Honda, C., Yokota, Y., Abe, M., Ogawa, Y., Miyamoto, H., Iwasaki, A., Pieters, C.M., Asada, N., Demura, H., Hirata, N., Terazono, J., Sasaki, S., Saiki, K., Yamaji, A., Torii, M., Josset, J.L., 2009. Long-lived volcanism on the lunar farside revealed by SELENE Terrain Camera. Science, 323(5916), 905-908.

Hiesinger, H., Head, J., Wolf, U., Jaumann, R., 2003. Ages and stratigraphy of mare basalts in Oceanus Procellarum, Mare Nubium, Mare Cognitum, and Mare Insularum. J. Geophys. Res-Atmos., 108(E7), 5065.

Huang, Q., Wang, T.M., Zhao, J.N., Meng, Z.G., 2018. Crustal and subsurface structures of Chang'E-4 lunar farside landingsite. Journal of Deep Space Exploration, 5(1), 41-49.

Ishihara, Y., Goossens, S., Matsumoto, K., Noda, H., Araki, H., Namiki, N., Hanada, H., Iwata, T., Tazawa, S., Sasaki, S., 2009. Crustal thickness of the Moon: Implications for farside basin structures. Geophy. Res. Lett., 36(19), 82-90.

Jolliff, B.L., 2012. New Views of the Moon. Geological Publishing House, Beijing.

Kim, K.J., Dohm, J.M., Williams, J.P., Ruiz, J., Hare, T.M., Hasebe, N., Karouji, Y., Kobayashi, S., Hareyama, M., Shibamura, E., Kobayashi, M., d'Uston, C., Gasnault, O., Forni, O., Maurice, S., 2012. The South Pole-Aitken basin region, 
Moon: GIS-based geologic investigation using Kaguya elemental information. Adv. Space Res., 50(12), 1629-1637.

Kramer, G.Y., Kring, D.A., Nahm, A.L., Pieters, C.M., 2013. Spectral and photogeologic mapping of Schrödinger basin and implications for post South Pole-Aitken impact deep subsurface stratigraphy. Icarus, 223(1), 131-148.

Lucey, P.G., Blewett, D.T., Jolliff, B., 2000. Lunar iron and titanium abundance algorithms based on final processing of Clementine ultraviolet/visible images. Geophys. Res-Planet., 105(E8), 20297-20305.

Meng, Z.G., Li, C., Ping, J.S., Huang, Q., Cai, Z.C., Alexander, G., 2018. Analysis about landing site selection and prospective scientific objectives of the Von Kármán crater in Moon farside. Journal of Deep Space Exploration, 5(1), 3-11.

Meng, Z.G., Li, X.Y., Chen, S.B., Zheng, Y.C., Shi, J.C., Wang, T.X., Zhang, Y.Z., Ping, J.S., Lu, Y., 2019. Thermophysical features of shallow lunar crust demonstrated by Typical Copernican craters using CE-2 CELMS data. JSTARS, 1-10.

Meng, Z.G., Yang, G.D., Ping, J.S., Cai, Z.C., Alexander, G., Edward, M.O., 2016. Influence of $\left(\mathrm{FeO}+\mathrm{TiO}_{2}\right)$ abundance on the microwave thermal emissions of lunar regolith. Sci. China Earth Sci., 59(7), 1498-1507.

Meng, Z.G., Zhang, J.D., Cai, Z.C., Ping, J.S., Tang, Z.S., 2017. Microwave thermal emission features of Mare Orientale revealed by CELMS data. IEEE J-STARS, 10(6), 2991-2998.

Moriarty, D.P., Pieters, C.M., Isaacson, P.J., 2013. Compositional heterogeneity of central peaks within the South Pole-Aitken basin. J. Geophys. Res-Planet., 118(11), 23102322.

National Research Council, 2007. Scientific context for the exploration of the Moon: a national research council space science board study. Washington D.C.: National Academies Press.

Ohtake, M., Matsunaga, T., Haruyama, J., Yokota, Y., Morota, T., Honda, C., Ogawa, Y., Torri, M., Miyamoto, H., Arai, T., Hirata, N., Iwasaki, A., Nakamura, R., Hiroi, T., Sugihara, T., Takeda, H., Otake, H., Pieters, C.M., Saiki, K., Kitazato, K., Abe, M., Asada, N., Demura, H., Yamaguchi, Y., Sasaki, S., Kodama, S., Terazono, J., Shirao, M., Yamaji, A., Minami, S., Akiyama, H., Josset, J.L., 2009. The global distribution of pure anorthosite on the Moon. Nature, 461(7261), 236-240.

Ouyang, Z.Y., 2005. Introduction to Lunar Science. China Astronautic Publishing House, Beijing, 68-137.

Pasckert, J.H., Hiesinger, H., Bogert, C.H., 2017. Lunar farside volcanism in and around the South Pole-Aitken Basin. Icarus, 299, 538-562.

Pieters, C.M, Gaddis, L., Jolliff, B., Duke, M., 2001. Rock types of South Pole-Aitken basin and extent of basaltic volcanism. J. Geophys. Res., 106(E11), 28001-28022

Snape, J.F., Fagan, A.L., Ennis, M.E., Pogue, J.N., Porter, S., Neal, C.R., Kring, D.A., 2010. Science-rich mission sites within South Pole-Aitken basin, part 2: Von Kármán crater. 41 st Lunar and Planetary Science Conference, 1533, 1857.
Stuart-Alexander D.E., 1978. Geologic map of the central far side of the moon. Alexander, 1-1047.

Wieczorek, M.A., 2007. Gravity and topography of the terrestrial planets. Planets and Moons, 10, 165-206.

Xiao, L., Qiao, L., Xiao, Z.Y., Huang, Q., He, Q., Zhao, J.N., Xue, Z.Q., Huang, J., 2016. Major scientific objectives and candidate landing sites suggested for future lunar explorations. Sci. Sin-Phys. Mech. Astron., 46(2), 029602.

Yamamoto, S., Nakamura, R., Matsunaga, T., Ogawa, Y., Ishihara, Y., Morota, T., Hirata, N., Ohtake, M., Hiroi, T., Yokota, Y., Haruyama, J., 2012. Olivinerich exposures in the South Pole-Aitken basin. Icarus, 218(1), 331-344.

Zhang, J., Miao, B.K., Liao, Q.Y., Jing, Y., Wang, H., 2011. The geological characteristics of the South Pole-Aitken basin on the Moon: the window to explore the deep composition of the Moon. Bulletin of Mineralogy, Petrology and Geochemistry, 30(2), 234-240.

Zheng, Y.C., Tsang, K.T., Chan, K.L., Zou, Y.L., Zhang, F., Ouyang, Z.Y., 2012. First microwave map of the Moon with Chang' E-1 data: the role of local time in global imaging. Icarus, 219(1), 194-210. 